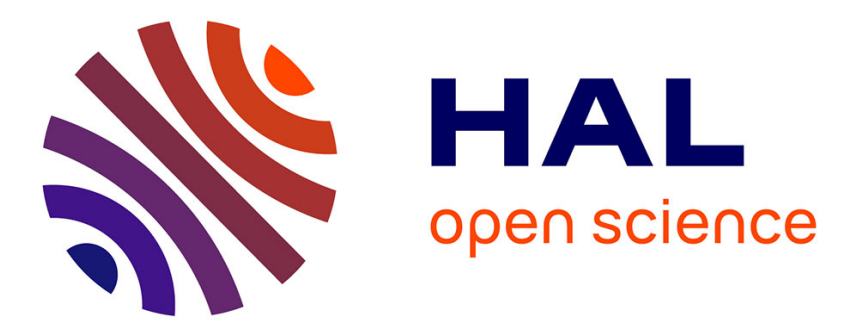

\title{
BASTA: A 95-GHz FMCW Doppler radar for cloud and fog studies
}

Julien Delanoë, Alain Protat, Jean-Paul Vinson, Williams Brett, Christophe Caudoux, Fabrice Bertrand, Jacques Parent Du Châtelet, Ruben Hallali, Laurent Barthès, Martial Haeffelin, et al.

\section{To cite this version:}

Julien Delanoë, Alain Protat, Jean-Paul Vinson, Williams Brett, Christophe Caudoux, et al.. BASTA: A 95-GHz FMCW Doppler radar for cloud and fog studies. Journal of Atmospheric and Oceanic Technology, 2016, 33 (5), pp.1023-1038. 10.1175/JTECH-D-15-0104.1 . insu-01278272

\section{HAL Id: insu-01278272 https://hal-insu.archives-ouvertes.fr/insu-01278272}

Submitted on 30 Jun 2016

HAL is a multi-disciplinary open access archive for the deposit and dissemination of scientific research documents, whether they are published or not. The documents may come from teaching and research institutions in France or abroad, or from public or private research centers.
L'archive ouverte pluridisciplinaire HAL, est destinée au dépôt et à la diffusion de documents scientifiques de niveau recherche, publiés ou non, émanant des établissements d'enseignement et de recherche français ou étrangers, des laboratoires publics ou privés. 


\title{
BASTA: A 95-GHz FMCW Doppler Radar for Cloud and Fog Studies
}

\author{
Julien Delanoë, ${ }^{\mathrm{a}}$ Alain Protat, ${ }^{\mathrm{b}}$ Jean-Paul Vinson, ${ }^{\mathrm{a}}$ Williams Brett,${ }^{\mathrm{a}}$ Christophe Caudoux, ${ }^{\mathrm{a}}$

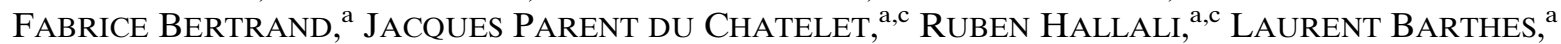 \\ MARTIAL HAEFFelin, ${ }^{\mathrm{d}}$ AND JeAN-CHARLES DuponT ${ }^{\mathrm{d}}$ \\ ${ }^{a}$ Laboratoire Atmosphères, Milieux, Observations Spatiales/UVSQ/CNRS/UPMC, Guyancourt, France \\ ${ }^{\mathrm{b}}$ Australian Bureau of Meteorology, Melbourne, Victoria, Australia \\ ${ }^{\mathrm{c}}$ Centre National de Recherches Météorologiques, Toulouse, France \\ ${ }^{\mathrm{d}}$ Institut Pierre-Simon Laplace, Palaiseau, France
}

(Manuscript received 5 May 2015, in final form 4 February 2016)

\begin{abstract}
Doppler cloud radars are amazing tools to characterize cloud and fog properties and to improve their representation in models. However, commercially available cloud radars (35 and $95 \mathrm{GHz}$ ) are still very expensive, which hinders their widespread deployment. This study presents the development of a lowercost semioperational 95-GHz Doppler cloud radar called the Bistatic Radar System for Atmospheric Studies (BASTA). To drastically reduce the cost of the instrument, a different approach is used compared to traditional pulsed radars: instead of transmitting a large amount of energy for a very short time period (as a pulse), a lower amount of energy is transmitted continuously. By using a specific signal processing technique, the radar can challenge expensive radars and provide high-quality measurements of cloud and fog. The latest version of the instrument has a sensitivity of about $-50 \mathrm{dBZ}$ at $1 \mathrm{~km}$ for 3 -s integration and a vertical resolution of $25 \mathrm{~m}$. The BASTA radar currently uses four successive modes for specific applications: the $12.5-\mathrm{m}$ vertical resolution mode is dedicated to fog and low clouds, the $25-\mathrm{m}$ mode is for liquid and ice midtropospheric clouds, and the 100- and 200-m modes are ideal for optically thin high-level ice clouds. The advantages of such a radar for calibration procedures and field operations are also highlighted. The radar comes with a set of products dedicated to cloud and fog studies. For instance, cloud mask, corrected Doppler velocity, and multimode products combining the high-sensitivity mode and high-resolution modes are provided.
\end{abstract}

\section{Introduction}

Doppler cloud radars are amazing tools to characterize cloud and fog properties and to improve their representation in models (Illingworth et al. 2007; Bouniol et al. 2010; Haeffelin et al. 2010; Maier et al. 2012; Dupont et al. 2012). Depending on the scientific application, they can be deployed from ground or ship (Moran et al. 1998; Kollias et al. 2007a), aircraft (Horie et al. 2000; Li et al. 2001; Wolde and Pazmany 2005; Delanoë et al. 2013; Hagen et al. 2014), or satellite (Stephens et al. 2002; Illingworth et al. 2015). The unique aspect of a Doppler cloud radar is its capability to describe at high vertical resolution (typically

Corresponding author address: Julien Delanoë, LATMOS/IPSL/ UVSQ/CNRS/UPMC, 11 Boulevard D'Alembert, Guyancourt 78280, France.

E-mail: julien.delanoe@latmos.ipsl.fr
50-100 m) cloud properties from all types of clouds, from thin cirrus to rain or snow. The high-frequency cloud radars are, however, subject to attenuation in rain cases, but they can still be used as long as the attenuation is corrected and not too strong (Lhermitte 1990). However, despite these obvious advantages, cloud radars are currently not deployed in coordinated networks as are other instruments, such as radiation instruments and lidars (e.g., Illingworth et al. 2007). The reason for this is that commercially available cloud radars are still very expensive (i.e., over 500 kEuros), hampering their widespread deployment. To overcome this problem, we explore in this paper the development of a lower-cost semioperational 95-GHz Doppler cloud radar. Most of the cost comes from the transmitter itself, as $95-\mathrm{GHz}$ pulsed radars need to transmit typically $1-2 \mathrm{~kW}$ to achieve the sensitivity required for cloud and fog studies. To drastically reduce the cost of the instrument, a different approach can be envisaged: instead of 
transmitting a large amount of energy for a very short time period (as a pulse), a lower amount of energy can be transmitted continuously. This technology is known as frequency-modulated continuous wave (FMCW) (Ligthart et al. 1986; Yamaguchi et al. 2006; Huggard et al. 2008; Sami 2009; Williams 2011). Such FMCW radars have been developed in the past for a wide range of applications, such as the characterization of ocean waves (Hauser et al. 1992). Very few developments have been geared toward the characterization of clouds and fog (e.g., Yamaguchi et al. 2006; Huggard et al. 2008; Thies et al. 2010). The main challenge of such a radar is to optimize the signal processing in order to compensate for the lack of power of the transmitter. Also, when a continuous signal is transmitted instead of a pulse, it becomes mandatory to find a way to "tag" the signal in order to identify where the energy comes from and the phase difference to compute the Doppler spectrum. Also, receiving continuous-wave $(\mathrm{CW})$ signals with an antenna very close to the transmitting antenna introduces additional challenges. In this paper we describe the FMCW radar project the Bistatic Radar System for Atmospheric Studies (BASTA) developed at the Laboratoire Atmosphères, Milieux, Observations Spatiales (LATMOS) and illustrate the potential of such a radar for cloud and fog studies. In section 2 we provide a general description of the BASTA radar and its applications. A technical description of the radar and the principle of this FMCW radar are then given in section 3. Section 4 describes the calibration aspect of the radar using different approaches. Comparisons of the BASTA radar against a state-of-the-art pulsed radar are discussed in section 5. Some remaining issues and technical points are presented in section 7. Conclusions and discussions on the next steps of this development are given in section 8 .

\section{General description of the BASTA concept and application}

\section{a. Main characteristics of the radars}

After a long development process that started in 2006, the first prototype of BASTA has been deployed at the Site Instrumental de Recherche par Télédétection Atmosphérique (SIRTA; Haeffelin et al. 2005) in Palaiseau, France. This first prototype has operated continuously since 2010 . The BASTA radar has even operated $100 \%$ of the time for the past 2 years. This illustrates the robustness of the design for potential operational deployment. Pictures of the instrument are shown in Fig. 1, where Fig. 1a illustrates the bistatic configuration of the radar. The two Cassegrain dishes $(60 \mathrm{~cm}$ in diameter) and all the electronic components are installed in a pressurized and insulated box $(154 \mathrm{~cm} \times 95 \mathrm{~cm} \times 74 \mathrm{~cm})$. The main

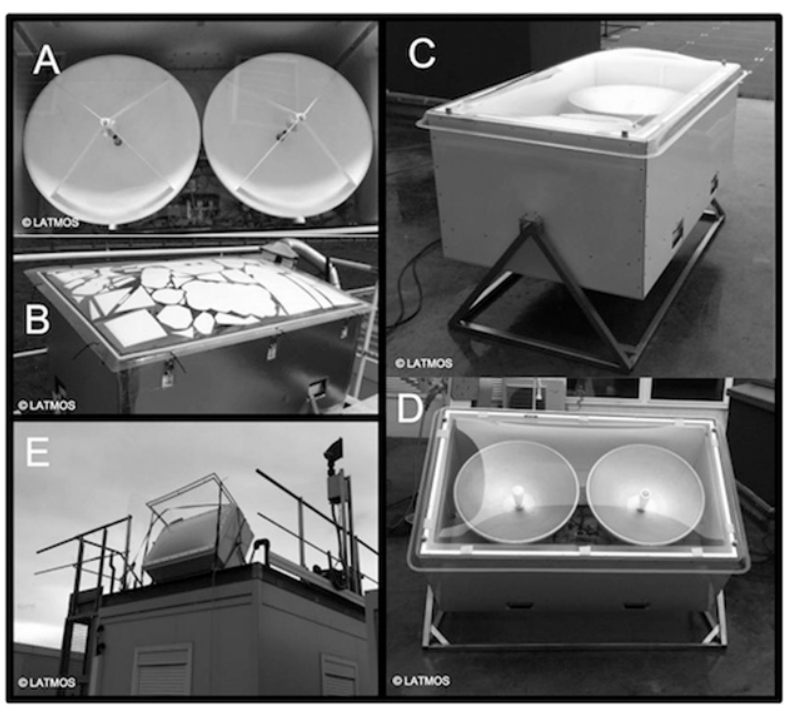

FIG. 1. Photos of the radar. (a),(b) Top view showing antennas and electronics, and the outside of the original prototype deployed at SIRTA. (c)-(e) BASTA-MOBILE in different positions.

characteristics of BASTA are given in Table 1. Power generators and the acquisition computer are stored in a shelter. Figure $1 \mathrm{~b}$ shows the outside of the radar, when covered by its radome. It is to be noted that a simple Plexiglass roof window is used instead of a very expensive radome. The performance of this radome fully satisfies the requirements. We estimated the two-way attenuation loss due to such a radome to be smaller than $3 \mathrm{~dB}$ by alternating measurements through a homogeneous cloud layer with and without the radome. Stickers are also used to protect the radar from direct solar radiation and to mitigate the greenhouse effect during summertime. The radar uses a solid-state transmitter $(0.5 \mathrm{~W})$ and measures both reflectivity and Doppler velocity. Building on the first prototype operating at SIRTA (BASTA-SIRTA), we developed a new generation of BASTA radars with very similar characteristics (Table 1) but with upgraded capabilities (slightly more powerful amplifier, i.e., $1 \mathrm{~W}$ ). The first one, which belongs to the Australian Bureau of Meteorology, is referred to as BASTA-BOM. The second one, which is owned by LATMOS, is referred to as BASTA-MOBILE. Both are dedicated to field campaign deployments. The three radars share the same dimensions and weight (around $60 \mathrm{~kg}$ ). Therefore, they are easy to manipulate and move. BASTA-BOM and BASTAMOBILE are almost identical.

\section{b. Radar measurements and dynamic range}

Figure 2 shows 3 weeks of continuous measurements of reflectivity (top panel) and Doppler velocity (bottom panel) at SIRTA as collected with the BASTAMOBILE. A large variety of meteorological conditions 
TABLE 1. Radar main specifications. ADC is the analog-to-digital converter.

\begin{tabular}{ll}
\hline \hline \multicolumn{1}{c}{ Radar type } & \multicolumn{1}{c}{$\begin{array}{c}\text { Bistatic FMCW, } \\
\text { single-polarization Doppler }\end{array}$} \\
\hline Operating frequency & $\approx 94.95 \mathrm{GHz}$ \\
Transmitter type & Solid state \\
System noise figure & $\approx 8 \mathrm{~dB}$ \\
Transmit power & $27-30 \mathrm{dBm}(0.5-1 \mathrm{~W})$ \\
Input power & $550 \mathrm{VA}$ \\
Dimensions and weight & \\
Weight & $60-70 \mathrm{~kg}$ \\
Length & $154 \mathrm{~cm}$ \\
Width & $95 \mathrm{~cm}$ \\
Height & $74 \mathrm{~cm}$ \\
Antenna type & $2 \mathrm{Cassegrain}-$ field \\
& parabolic dishes \\
Diameter & $0.60 \mathrm{~m}$ \\
Gain & $54 \mathrm{~dB} i$ \\
Beamwidth & $0.4^{\circ}$ \\
Data acquisition/processing & ADC/FPGA \\
$\quad$ system & \\
Chirp analyze time & $40-80 \mu \mathrm{s}$ \\
Sampling rate & $51.2 \mathrm{MHz}$ \\
Algorithm used & PPP \\
Archive data format & netCDF \\
Measurements & Reflectivity and \\
Min distance to valid signal & Doppler velocity \\
\hline & $40 \mathrm{~m} \mathrm{(depending} \mathrm{on} \mathrm{resolution)}$ \\
\hline &
\end{tabular}

and cloud types is observed, including low clouds, fog, cirrus, and liquid precipitation. The vertical resolution is $25 \mathrm{~m}$ and the integration time is set to $3 \mathrm{~s}$, with a maximum range of $12 \mathrm{~km}$ and a Nyquist velocity of $5 \mathrm{~m} \mathrm{~s}^{-1}$. This example shows the capability of the radar to operate continuously for uninterrupted periods of time and to detect all types of clouds with its sensitivity of about $-44 \mathrm{dBZ}$ at $1 \mathrm{~km}$ corresponding to this setup (sensitivity is discussed hereafter). Note that the background noise has been removed (see section $2 \mathrm{~d}$ ).

Figure 3 illustrates the statistical performances of the three radars (BASTA-SIRTA, BASTA-BOM, and BASTA-MOBILE) at 25-m resolution and 3-s integration for different time periods. Figures $3 \mathrm{a}-\mathrm{f}$ represent the probability distribution of the calibrated and rangecorrected reflectivity versus altitude. Only reflectivities above noise level are included. The noise level is determined using the farthest clear-sky gate from the radar for each radial. In case there is no clear-sky gate available, a default value is used based on the latest available values. The BASTA-SIRTA distribution (Fig. 3a) is the accumulation of one year (2014) of data at SIRTA with the first prototype. Figure $3 \mathrm{~b}$ shows statistics derived from 9 months of data collected with BASTA-BOM at Darwin International Airport, Australia, from March to December 2014. Note that the reflectivity has not been corrected from gaseous attenuation. This panel illustrates the capability of BASTA radars to observe clouds up to $12 \mathrm{~km}$. The BASTA-BOM was deployed at a tropical latitude (Darwin, northern Australia), characterized by heavy precipitation during the wet season and a melting layer at about $5-\mathrm{km}$ height. The small change in $0^{\circ} \mathrm{C}$ isotherm altitude during the wet season explains the sharp drop in reflectivity at $5 \mathrm{~km}$. The altitude of the melting layer is not as readily observed in the midlatitude data given the comparably larger seasonal variability of the melting layer height. During the development phase of the two most recent radars, we carried out several direct comparisons between the prototype and the two other radars operating at the same time and place. A

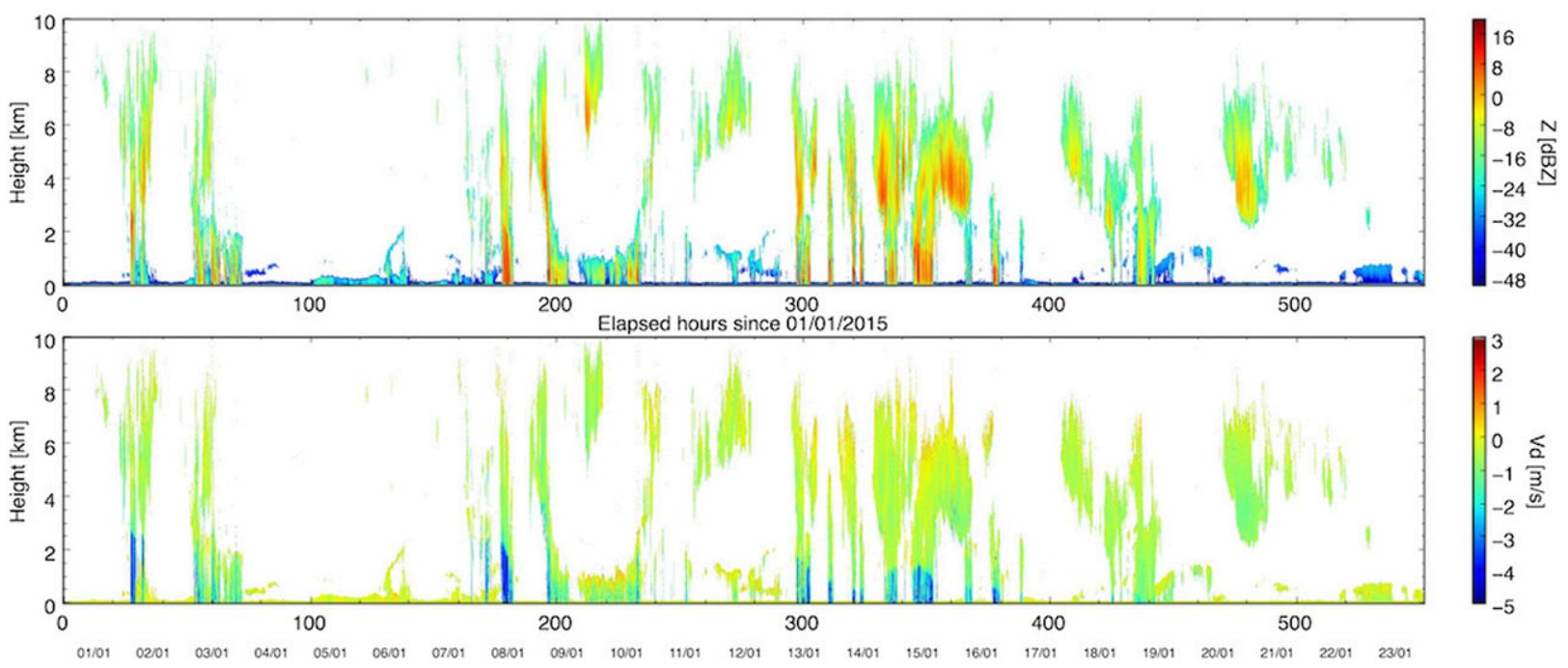

FIG. 2. Range-corrected reflectivity and Doppler velocity at 25-m resolution (3-s integration). Data collected at SIRTA from 1 to 23 Jan 2015. 

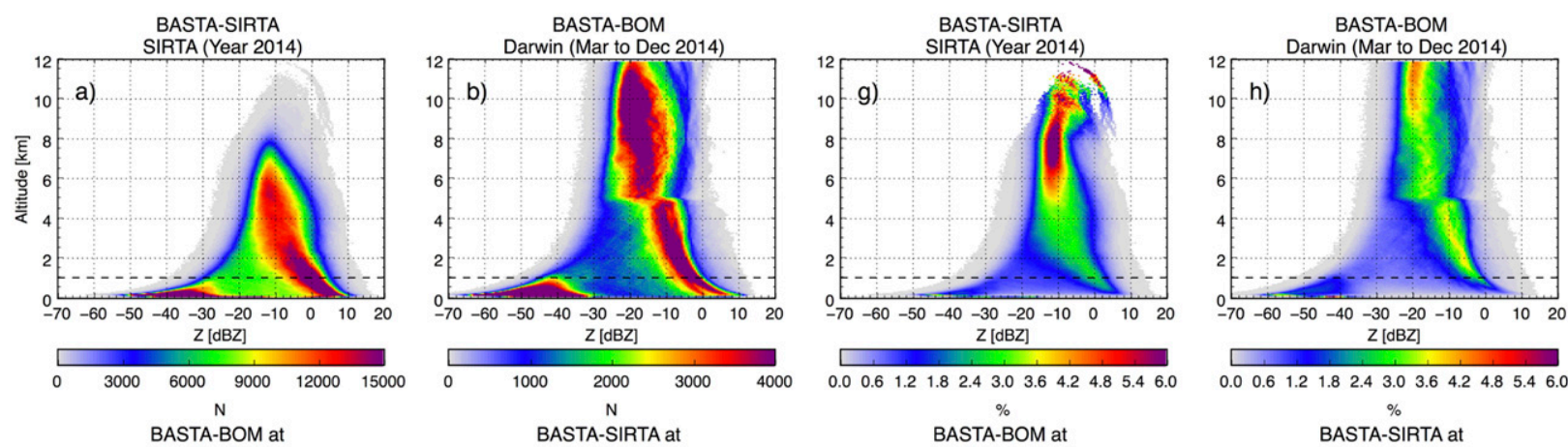
BASTA-SIRTA at
SIRTA (20-31 Jan 2014)
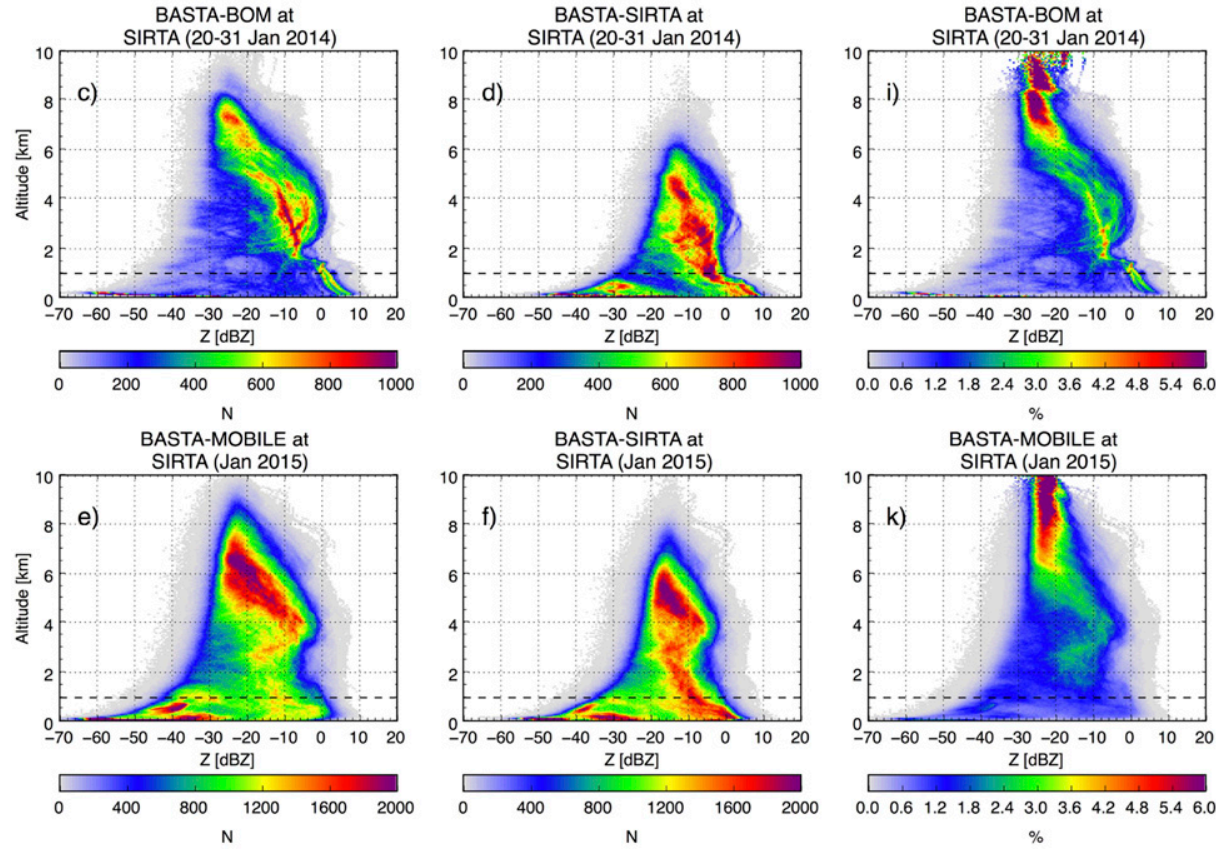
$\%$
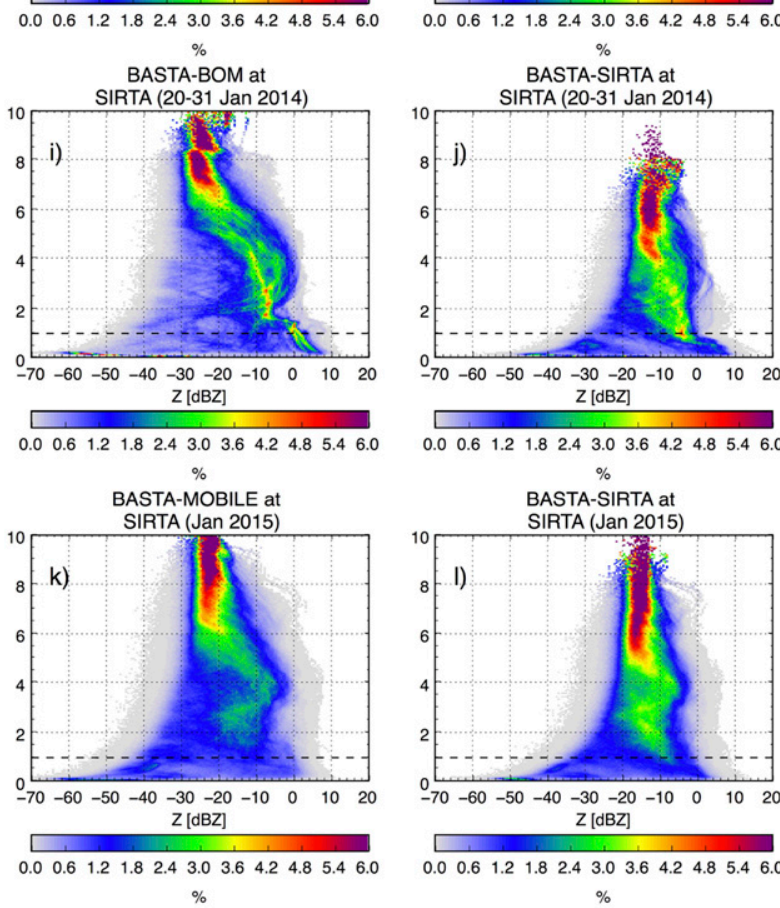
BASTA-SIRTA at

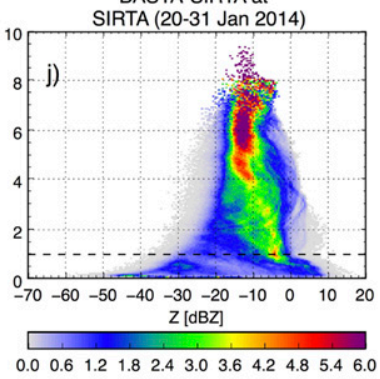
$\%$

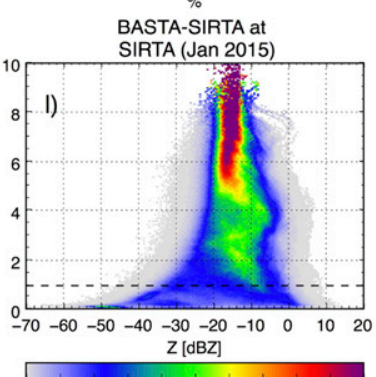

$0.0 \quad 0.6 \quad 1.2 \quad 1.8 \quad 2.4 \quad 3.0 \quad 3.6 \quad 4.2 \quad 4.8 \quad 5.4 \quad 6.0$ $\%$

FIG. 3. Altitude-Z distributions for BASTA-SIRTA, BASTA-BOM, and BASTA-MOBILE for different time periods. (a)-(f) Color scale represents the number of hits in each reflectivity and altitude bin. (g)-(l) As in (a)-(f), but normalized by the total number at each altitude. Dashed line highlights the 1-km range.

direct comparison of the performances of the BASTABOM radar against the first prototype is shown in Figs. 3c and $3 \mathrm{~d}$ for the last 10 days of January 2014 at SIRTA. Despite a small amount of data, the better sensitivity of the BASTA-BOM radar is obvious, especially for highaltitude clouds, where the BASTA-BOM shows much more hits above $6 \mathrm{~km}$. One month of data has been collected with BASTA-MOBILE at SIRTA (January 2015). The results are presented in Figs. $3 e$ and $3 f$ for the same period. BASTA-MOBILE, due to its better sensitivity, also exhibits more hits above $6 \mathrm{~km}$ with a difference in sensitivity larger than $10 \mathrm{~dB}$. To better characterize the sensitivity and the measurement dynamics of the radars, the same distributions but normalized by the total number of measurements at a given altitude are shown in Figs. 3g-l. Percentages smaller than $0.1 \%$ are not displayed. We estimate the overall sensitivity of each radar at $1 \mathrm{~km}$ as -35 , -49 , and $-44 \mathrm{dBZ}$ for BASTA-SIRTA, BASTA-BOM, and BASTA-MOBILE, respectively, for 3-s integration. These results (not shown) confirmed the statistical difference in sensitivity between the radars as observed in Fig. 3 . It is important to mention though that this sensitivity changes with atmospheric conditions and noise-removing technique. Figure 3 also allows for an estimation of the dynamic range of these radars at $1 \mathrm{~km}$. This dynamic range is about 42,60 , and $55 \mathrm{~dB}$ for BASTA-SIRTA, BASTABOM, and BASTA-MOBILE, respectively.

\section{c. Four modes for different applications}

Clouds in the troposphere are characterized by a variety of geometrical and optical thicknesses at different heights. Designing the most appropriate cloud radar parameters requires taking into account our current knowledge of these cloud properties. Given the rangesquared loss in sensitivity, it is much more challenging to detect thin cirrus clouds in the tropics (found at ranges 
TABLE 2. Radar characteristics for each mode.

\begin{tabular}{|c|c|c|c|c|}
\hline Range resolution (m) & 12.5 & 25 & 100 & 200 \\
\hline Unambiguous range $(\mathrm{km})$ & 6 & 12 & 12 & 12 \\
\hline Unambiguous velocity $\left(\mathrm{m} \mathrm{s}^{-1}\right)$ & 9.87 & 4.935 & 4.935 & 4.935 \\
\hline Pulse repetition period $\left(T_{\text {rep }}\right)(\mu s)$ & 80 & 160 & 160 & 160 \\
\hline Chirp analysis time $\left(T_{a}\right)(\mu s)$ & 40 & 80 & 80 & 80 \\
\hline Chirp band $(\mathrm{MHz})$ & $90 \pm 12$ & $90 \pm 6$ & $90 \pm 1.5$ & $90 \pm 0.75$ \\
\hline FFT points number & 2048 & 4096 & 4096 & 4096 \\
\hline Gate number & 480 & 480 & 120 & 60 \\
\hline
\end{tabular}

up to $18 \mathrm{~km}$ ) than to detect drizzling stratocumulus clouds. It is also crucial to detect some types of clouds with as high a vertical resolution as possible, in order to accurately characterize the altitudes of their base and top. It is particularly important for geometrically thin liquid cloud layers and fog. However, we cannot have both in one operating mode, as increasing range resolution readily comes at the expense of sensitivity.

As a result, cloud radars typically use more than one mode of operations. For instance, cloud radars deployed by the U.S. Department of Energy (DOE) Atmospheric Radiation Measurement (ARM) Program use a "general" mode with intermediate sensitivity and range resolution, but also a "precipitation" mode, a "cirrus" mode using pulse compression, and a "boundary layer" mode (Kollias et al. 2007b) to optimize the detection of these different types of clouds. Following this requirement that the detection of different types of clouds should be optimized, the BASTA radars use four distinct modes, characterized by different range resolutions: $12.5,25,100$, and $200 \mathrm{~m}$. The radar characteristics of each mode are presented in Table 2. Since the integration time is set to $3 \mathrm{~s}$ for the modes, each mode is therefore repeated every $12 \mathrm{~s}$. The real-time processing is sufficiently fast to process data during the acquisition time. The $25-\mathrm{m}$ resolution mode covers the range $125 \mathrm{~m}$ to $12 \mathrm{~km}$ with sensitivity suitable to detect most low-level liquid clouds and thick cirrus. The $12.5-\mathrm{m}$ resolution mode is dedicated to the low clouds, fog, and precipitation. In this mode, the 6-dB loss in sensitivity relative to the 25 -m mode is balanced by the closer range of fog and thin liquid clouds or the high reflectivity of rain. Also, this 12.5 -m mode is limited to $6 \mathrm{~km}$, but the Nyquist velocity is extended to $10 \mathrm{~m} \mathrm{~s}^{-1}$, which is particularly relevant for rain. This very high-vertical resolution mode is ideal for fog and low-stratus studies (Maier et al. 2012; Dupont et al. 2012).

Figure 4 shows two examples of low-cloud/fog measurements. The first case is the evolution of a drizzling stratus sampled for over $70 \mathrm{~h}$ from 21 December 2014. The second one shows the life cycle of a persistent fog from 5 January 2015. The minimum range measurement for the $12.5-\mathrm{m}$ mode is about $40 \mathrm{~m}$ for the Doppler velocity, which corresponds to three radar gates. Note that this short minimum distance measurement is a benefit from the bistatic nature of the instrument. Unfortunately, we cannot use the very first gates due to the coupling effect (i.e., direct interaction between the antennas at very close range). The reflectivity measured between 40 and $240 \mathrm{~m}$ must be used with caution due to the beam overlap issue and the fact that the far-field approximation is not valid (minimum $240 \mathrm{~m}$ at this wavelength with 60 -cm dishes). Note that Sekelsky (2002) proposed a correction for the near-field reflectivity.

The two other modes, which are mainly dedicated to the detection of thinner cirrus clouds, 100 and $200 \mathrm{~m}$, are 6 and $9 \mathrm{~dB}$ more sensitive, respectively, than the $25-\mathrm{m}$ mode. Figure 5 illustrates the four mode measurements for the 18 January 2014 case with the BASTA-BOM radar at SIRTA during its test phase. The two top panels depict the range-corrected and calibrated reflectivity and Doppler velocity. We clearly see the impact of the mode on the sensitivity and the capacity to measure at very close range to the radar. From this example we observe a noise contamination from 1000 UTC until the end of the day above $5 \mathrm{~km}$ for the $12.5-\mathrm{m}$ mode.

This artifact can be easily removed using the information from the other modes. Note that this rise in the noise floor appears only if the meteorological signal is very strong in the vicinity of the radar and the meteorological target has a weak echo above this strong signal. This is due to the imperfections of one of the electronic parts (single sideband mixer defined later in the text) and the choice of the central chirp frequency. It does not affect all modes in the same way, as it also depends on the frequency width of the chirp. We are currently investigating a solution to remove this artifact by changing the central chirp frequency. Note that it is possible to select four modes or one of them and the integration time from the radar control software.

\section{d. Radar products}

Radar products are currently developed for the BASTA radar, all relying on the same techniques as commonly used for pulsed radars. The background noise 

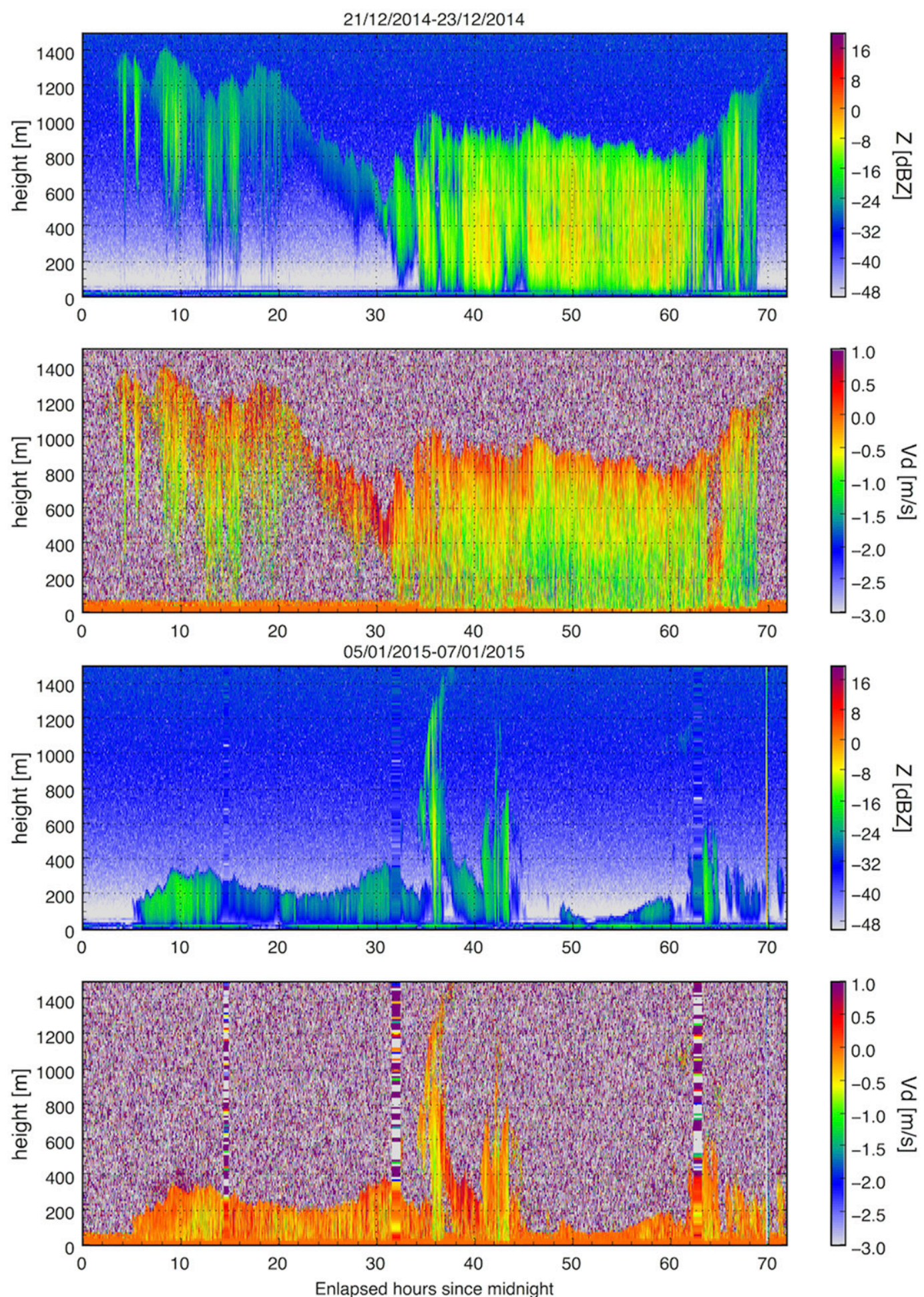

FIG. 4. Fog/low-cloud measurements: Doppler velocity $V_{d}$ and radar reflectivity $Z$. Data collected by BASTAMOBILE at SIRTA from 21 to 23 Dec 2014 and from 5 to 7 Jan 2015. Vertical stripes in the second example are due to electrical power disruption; the radar restarted automatically. 

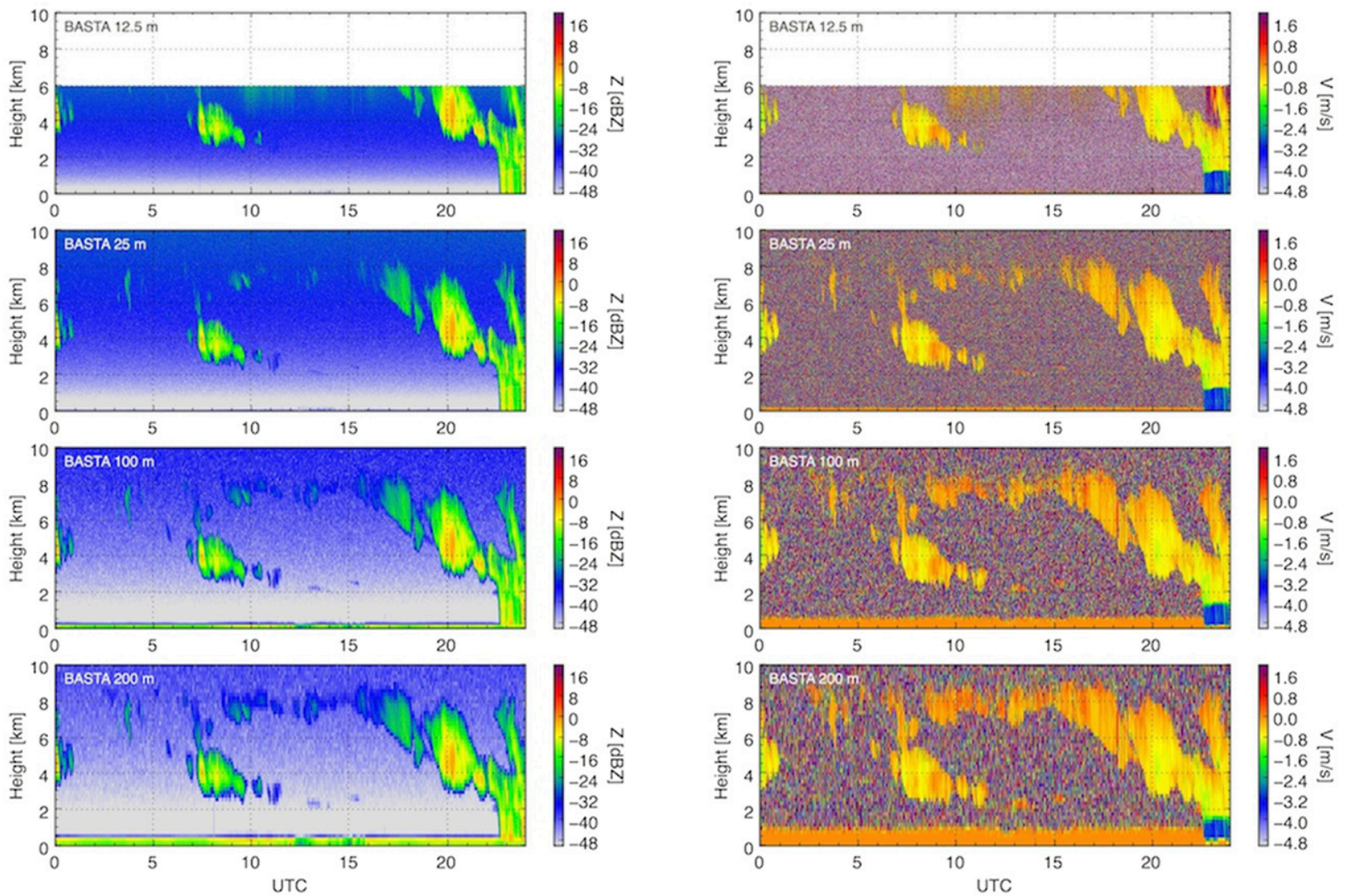

FIG. 5. Range-corrected reflectivity and Doppler velocity at 12.5-, 25-, 100-, and 200-m resolution. Data collected at SIRTA on 18 Jan 2014.

is first removed using a thresholding technique and the isolated pixels are removed using erosion image processing. The mean and standard deviation of the backscattered power signal at the far end of the radial is used to work out the threshold value to be used. In case of cloud contamination, we use a reference value that has been derived from a longer monitoring of the noise characteristics for long clear-sky periods preceding the current observation. Note that the background noise value is by definition the same for the four modes. This is crucial for the $12.5-\mathrm{m}$ mode, as the range bins at $6 \mathrm{~km}$ are much more likely to include cloud echoes than at $12 \mathrm{~km}$ in the midlatitudes. We also use a structure recognition technique based on the standard deviation of the Doppler velocity in a running window. The velocity offers a higher contrast than the reflectivity. The Doppler velocity varies within the range $\left[-V_{\max },+V_{\max }\right]$, where $V_{\max }$ is the Nyquist velocity. As a result, if the droplet velocity is faster than $V_{\max }$, the velocity will be folded within that range. Fortunately, the unfolding process is straightforward. We use a gate-to-gate correction initialized at the first gate by the measured value, assuming that most of the time the vertical air velocity is small near the ground, and as a result the Doppler velocity is almost equal to the reflectivityweighted terminal fall speed. We can also use the rain detection to check the sign of the velocity. The 25-, 100-, and 200-m modes have a Nyquist velocity of around $5 \mathrm{~m} \mathrm{~s}^{-1}$. In very ambiguous cases, we use the velocity measured by the 12.5 -m mode (for which $V_{\max } \approx 10 \mathrm{~m} \mathrm{~s}^{-1}$ ) to unfold the Doppler velocity from the other modes.

We also developed a synergistic product that combines all modes, so that nonexpert users can readily use a single reflectivity and Doppler velocity estimate. To construct this product, the $25-\mathrm{m}$ mode is used as a baseline. The $12.5-\mathrm{m}$ measurements are then averaged at the resolution of the other modes and are used to correct the folded Doppler velocities of the other modes. The most sensitive modes $(100$ and $200 \mathrm{~m})$ are oversampled onto the $25-\mathrm{m}$ resolution grid. An illustration of this radar product is given in Fig. 6, where the top panel shows the multimode reflectivity and the middle panel shows the Doppler velocity measured on 19 January 2014 at SIRTA using the BASTA-BOM radar. The bottom panel indicates from which mode the information comes. A dedicated fog product is also similarly derived at the $12.5-\mathrm{m}$ resolution, using the $12.5-\mathrm{m}$ 

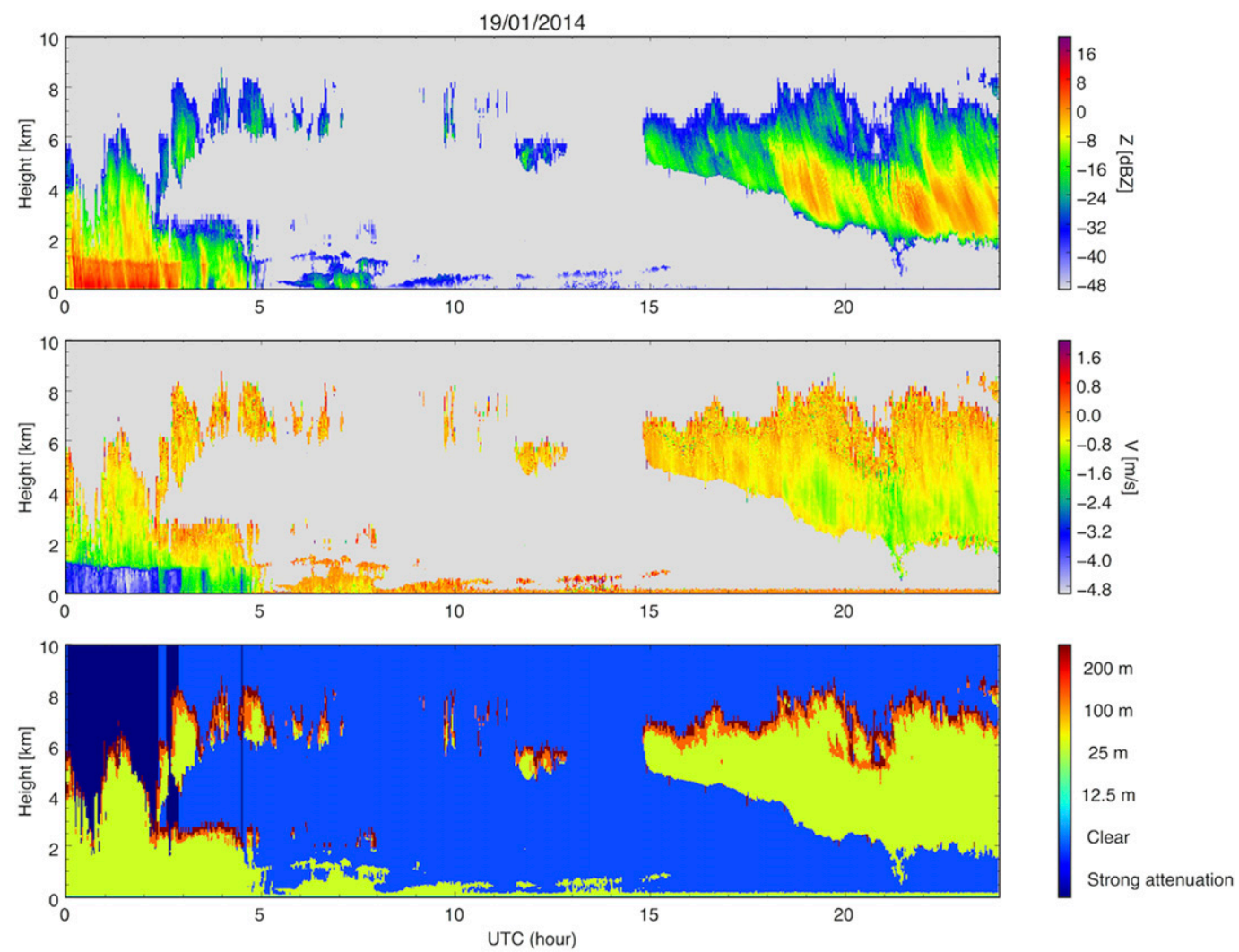

FIG. 6. Example of merged data collected on 19 Jan 2014: (top) reflectivity, (middle) Doppler velocity, and (bottom) data source $(12.5 / 25 / 100 / 200 \mathrm{~m})$.

mode as the baseline, and oversampling the other modes at this resolution. A detection of the melting layer is also available in case of stratiform rain (not shown). Several radar-only algorithms will also be adapted in the near future to derive ice/liquid water content and more cloud microphysical properties from the BASTA observations (Matrosov and Heymsfield 2000; Hogan et al. 2006; Deng and Mace 2006; Protat et al. 2007; Delanoë et al. 2007). The BASTA radar can also be combined with lidar and microwave radiometers to improve the accuracy of the cloud microphysical products (Löhnert et al. 2001; O'Connor et al. 2005; Illingworth et al. 2007; Delanoë and Hogan 2008).

\section{Technical description and principle of the radar \\ a. FMCW principle}

Basically all radars work on the time delay between the transmitted wave and the received wave, while the latter is traveling at the speed of light. This information is obtained by correlating the transmitted and backscattered signals. The signal processing allows one to compute the energy backscattered by the radar target but also to determine whether the observed target is moving toward or away from the radar. This processing is clearly facilitated by using a wave packet (usually referred to as "pulses"), where energy is released for short time periods interleaved with silent periods. Since we know exactly which wave packet has been interacting with the target, the range determination becomes obvious. Note that the pulse repetition frequency (PRF) and the pulse length define the performance and capability of the radar (ambiguous distance, ambiguous velocity, blind zone). Unfortunately, the pulse approach requires the emission of a huge amount of energy for a very short period of time, which requires a very expensive transmitter (typically $250 \mathrm{kEuros}$ for $1.5 \mathrm{~kW}$ ). The FMCW technique relies on the same radar principle except that the energy is transmitted continuously without any dead time. The pulse is replaced by a modulation of the radar frequency. Consequently, most of the challenge with such radars lies in the signal processing. Figure 7 describes the principle of the FMCW radar. The radar frequency varies between $F_{0}-\Delta F$ and $F_{0}+\Delta F$, where $F_{0}$ is the central frequency and $\Delta F$ represents half of the frequency 


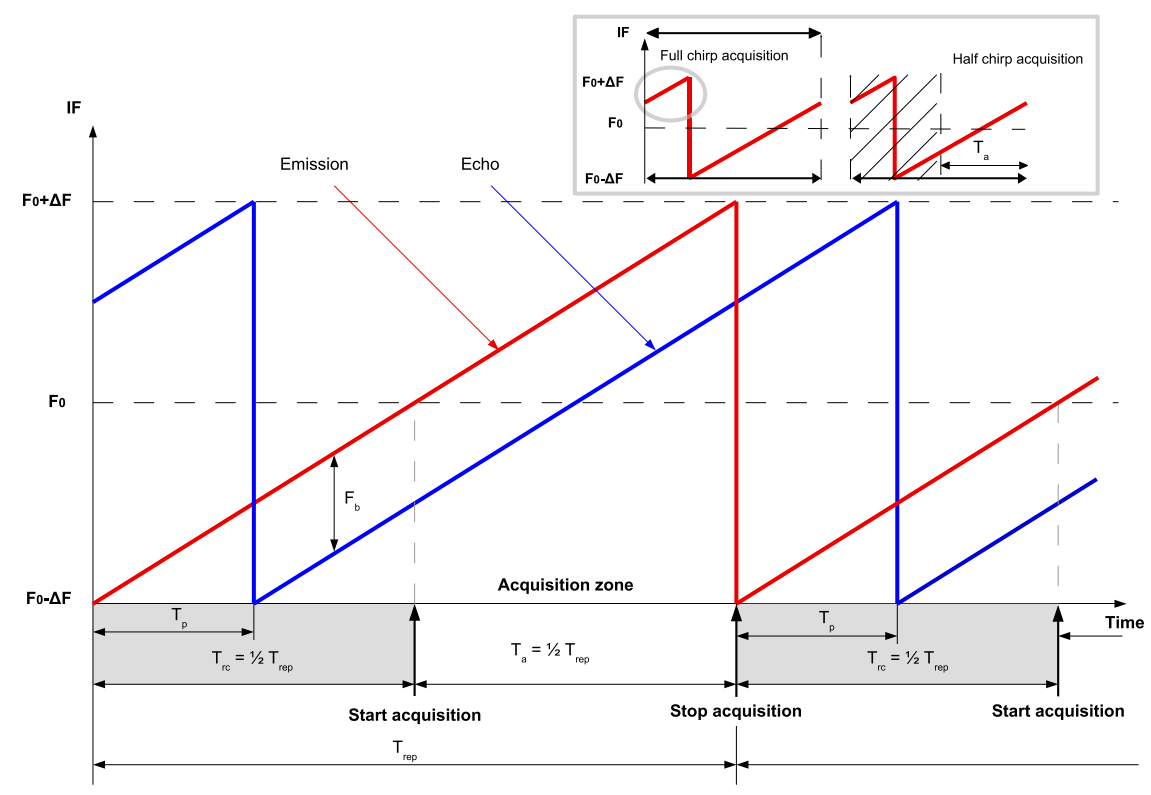

FIG. 7. FMCW principle and an example of the impact of using half of the chirp (gray box).

band. A linear chirp is used to control the radar frequency changes. For example, the red chirp corresponds to the transmitted signal and covers the $F_{0}-\Delta F$ and $F_{0}+\Delta F$ range in $T_{\text {rep }}$ time. Once we get a return from the target, the radar receives the echo signal (blue). The signal backscattered by the target is received with a time delay $T_{p}$. This time delay corresponds to a distance $D$, which is defined by the following equation:

$$
D=T_{p} \times \frac{c}{2}
$$

where $c$ is the electromagnetic-wave propagation speed. After convolution of the emitted and received signals, $T_{p}$ is associated with a beat frequency $F_{b}$ as shown in Fig. 7 such that

$$
F_{b}=2 \Delta F \times \frac{T_{p}}{T_{\text {rep }}} .
$$

Note that in our system the acquisition starts at $T_{a}=T_{\mathrm{rep}} / 2$ in order to avoid discontinuities due to extra echo returns, as shown in the gray box included in Fig. 7. We clearly see the interest of using only half of the chirp, as we avoid the contamination from other chirps (gray circle). Note that it does not suppress the contamination from the target exceeding the maximum range; however, the return is weak enough to remain invisible. As a result there is a loss in sensitivity of $3 \mathrm{~dB}$, but we noticeably reduce typical FMCW artifacts. These artifacts, created by chirp returns, results in a frequency discontinuity and consequently in an increase of background noise within the radial. As a result the whole profile is contaminated and cannot be used.

As with any radar we can then compute the following:

the ambiguous distance $\left(D_{a}\right)$ :

$$
D_{a}=T_{a} \times \frac{c}{2}
$$

the ambiguous velocity:

$$
V_{a}=\frac{c}{4 \times F_{0} \times T_{\text {rep }}}
$$

and the range resolution:

$$
r=\frac{c}{2 \times 2 \Delta F} .
$$

Each mode is characterized by a dedicated chirp, that is, a central frequency and a half bandwidth.

\section{b. BASTA radar technical description}

The BASTA radar operates at $94.95 \mathrm{GHz}$. At such high frequency, the radio frequency (RF) components are either not available or very expensive. Fortunately, RF sources are available and much cheaper at a lower frequency. As a result, we use a source at $15.825 \mathrm{GHz}$ for the BASTA radar, as explained in what follows. Note that in that case, the central frequency of the chirp $\left(F_{0}\right)$ is not at $94.95 \mathrm{GHz}$. The radar diagram is presented in 


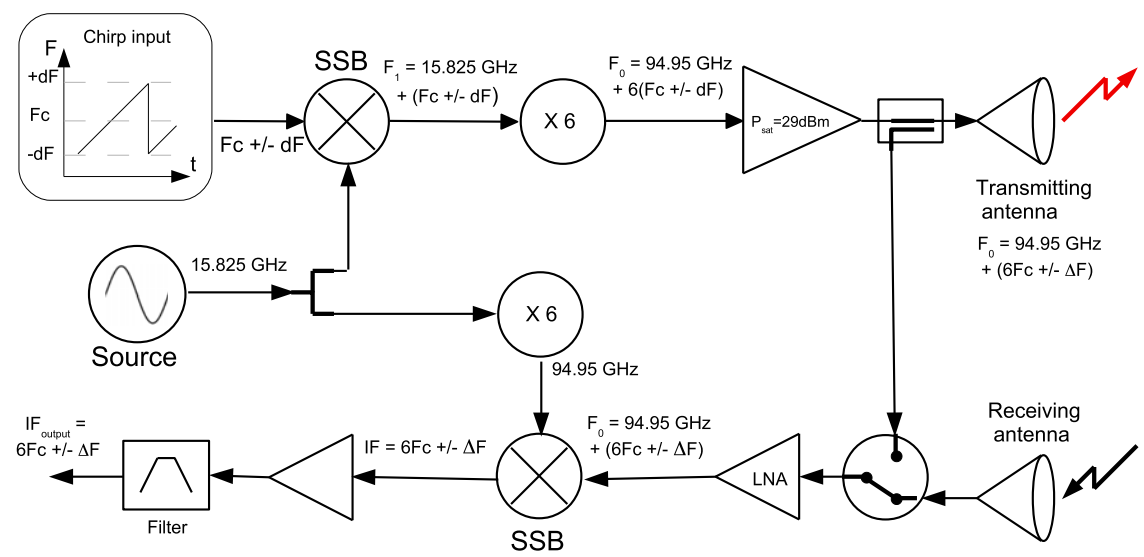

FIG. 8. Radar block diagram.

Fig. 8. The technical description can be separated into three parts: the transmitter, the receiver, and the acquisition/ signal processing.

\section{1) Transmitter CHAiN}

The frequency-modulated signal is generated from two signals. First, a single-sideband (SSB) mixer is triggered using a chirp frequency $\left(F_{\text {chirp }}\right)$. It allows one to upconvert a stabilized source frequency at $15.825 \mathrm{GHz}$ to a $F_{1}$ frequency, as shown in Fig. 8 . Term $F_{1}(\mathrm{GHz})$ is defined as follows:

$$
F_{1}=15.825+F_{\text {chirp }},
$$

with $F_{\text {chirp }}=F_{c} \pm d F$. Term $F_{c}$ is the central frequency and $d F$ is defined as the half bandwidth of the chirp. Then, the second step of the signal generation makes use of a multiplier. Term $F_{1}$ is multiplied by 6 to obtain $F_{0}$. The derived signal is amplified (amplifier 0.5 or $1 \mathrm{~W}$ ) and transmitted to the antenna via the waveguides. As a result $F_{0}$ can be expressed as

$$
F_{0}=6 \times F_{1}=94.95+6 \times F_{\text {chirp }}=94.95+6 F_{c} \pm \Delta F,
$$

where $\Delta F=6 d F$.

\section{2) RECEIVER CHAIN}

The receiver chain is based on a single downconversion. The received signal is amplified through the low-noise amplifier (LNA). The received signal is mixed with a signal at $94.95 \mathrm{GHz}$ obtained from the source at $15.825 \mathrm{GHz}$ multiplied by 6 . The derived signal $I F$, defined as

$$
I F=6 F_{c} \pm \Delta F,
$$

is amplified and filtered.

\section{3) ACQUiSITION AND SIGNAL PROCESSING}

The analog signal $I F$ from the receiver chain is digitized. The signal processing step is illustrated in Fig. 9. It is based on the impulse response ( $R$, complex number) in frequency in both module and phase for different radials. The impulse response is the result of a numerical demodulation of the received chirp

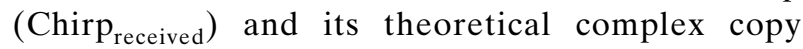
(Chirp reference $)$ weighted by a Hanning window, which is a good compromise between frequency resolution and spectral leakage:

$R=\operatorname{FFT}\left(\right.$ Chirp $_{\text {received }} \times$ Chirp $_{\text {reference }} \times$ Hanning $)$.

At this stage, the output signal is similar to a signal derived from a pulsed radar. The reflectivity and Doppler velocity are proportional to the module and the argument of a complex number PPP, respectively. PPP is computed using pulse-pair processing following this expression:

$$
\mathrm{PPP}=\frac{1}{n-1} \sum_{i=0}^{i=n-1} R_{i} \times R_{i+1}^{*},
$$

where the asterisk $(*)$ refers to the complex conjugate of the impulse response. A field-programmable gate array (FPGA) is in charge of the acquisition and the signal processing. The main advantage of this system is the real-time processing capability.

\section{Calibration}

Although cloud detection does not require any calibration, it is a crucial issue for the retrieval of cloud microphysical properties (such as liquid or ice water content). There are different ways to calibrate a cloud 


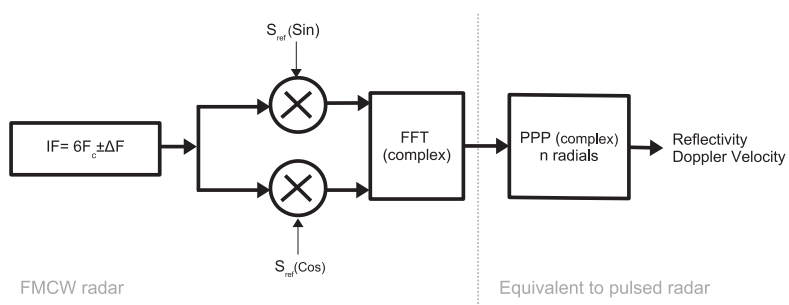

FIG. 9. FMCW signal processing.

radar: knowing exactly all the constants and variables described in the radar equation (internal calibration), or using meteorological or metal targets of reference (external calibration). Unfortunately, it remains very difficult to determine the exact power budget through electronic components and various gains. Therefore, the target approach (artificial or meteorological) remains the best way to calibrate radars. For calibration purposes we benefit from the small size, light weight, and narrow beamwidth $\left(0.4^{\circ}\right)$ of the BASTA radar. The radar can be mounted on a swing system to point manually horizontally or at different elevations. This is illustrated in Figs. 1c and 1d. On 25 June 2013 we carried out the first calibration procedure with the radar prototype (BASTA-SIRTA). The radar was on a shelter roof at $3 \mathrm{~m}$ above the ground and pointing toward a trihedral target, with a known backscatter, set at 560-m distance and mounted on a 20-m-tall mast. In Fig. 10 we illustrate the measurements collected for a few hours on that day. Figure 10a shows the average power profile measured by the radar between 0 and $1 \mathrm{~km}$; gray lines represent the standard deviation envelope. Similarly, Fig. 10b shows the average velocity profile. Note that during that period, the relative humidity was less than $45 \%$ and led to a two-way atmospheric attenuation at $95 \mathrm{GHz}$ smaller than $0.5 \mathrm{~dB}$ between the radar and the target. We clearly distinguish the target return for two gates (550 and $575 \mathrm{~m}$ ) with a maximum power return between 212 and 214 (Figs. 10a and 10c) in arbitrary unit (decibel). Note that trees are also backscattering the waves. However, the Doppler velocity is not equal to zero contrary to the trihedral target due to the trees' motion (Fig. 10b). The measurements were made using the $25-\mathrm{m}$ resolution mode. It is then possible, knowing the theoretical return of the corner reflector, to evaluate the calibration value to convert the uncalibrated power measured by the radar into reflectivity value ( $\mathrm{dB} Z)$.

Note that the other modes are calibrated using this value and are taking into account the range resolution. BASTA-BOM and BASTA-MOBILE have been calibrated using BASTA-SIRTA as reference. The evolution of the calibration value is not presented in this study, but it will be thoroughly assessed in a future study. It is
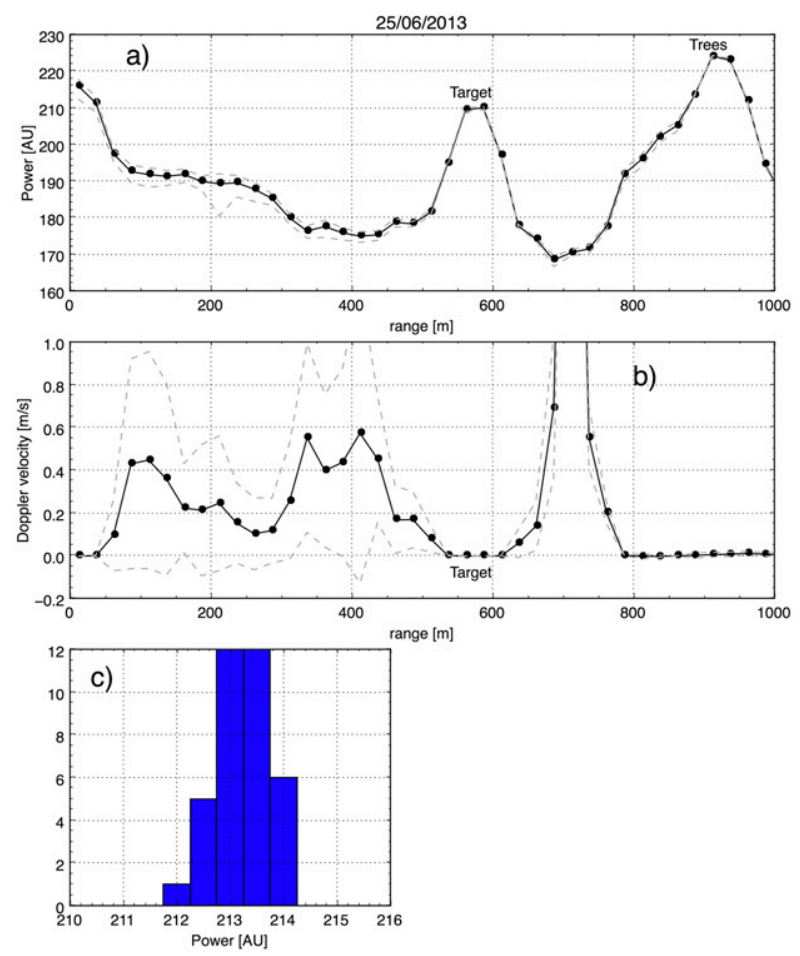

FIG. 10. Calibration approach example for BASTA SIRTA on 25 Jun 2013. Calibration is carried out using the radar pointing horizontally toward a trihedral target. (a),(b) Average raw reflectivity and velocity, respectively, as a function of radar range. Gray dashed lines represent mean plus/minus standard deviation. (c) Histogram of the energy backscattered by the target.

obvious that such a measurement must be repeated many times a year. Fortunately, we will see in the next section that the value presented here is a very good proxy.

Hogan et al. (2003) proposed an elegant technique to calibrate $95-\mathrm{GHz}$ radar, and we have reproduced the same experiment using simultaneous measurements from BASTA-SIRTA (vertically pointing, Fig. 1b) and BASTA-MOBILE at $30^{\circ}$ elevation (Fig. 1e) at the SIRTA observatory. Rain rate was measured during a rain event by the dual-beam spectropluviometer (DBS; Delahaye et al. 2006), which was developed at LATMOS and operated at SIRTA only a few meters away from the radars. The concept of the Hogan et al. (2003) calibration technique is to simultaneously measure radar reflectivity at 500-m range and rain rate in light rain, and to compare the obtained relationship between these two measurements to that predicted assuming a shape for the raindrop size distribution and assuming that the path attenuation over a few hundred meters in light rain is small or corrected from attenuation. Note that in that case, the radome must remain as dry as possible to avoid attenuation due to the wet radome. Hogan et al. (2003) positioned their radar at a $30^{\circ}$ elevation and 

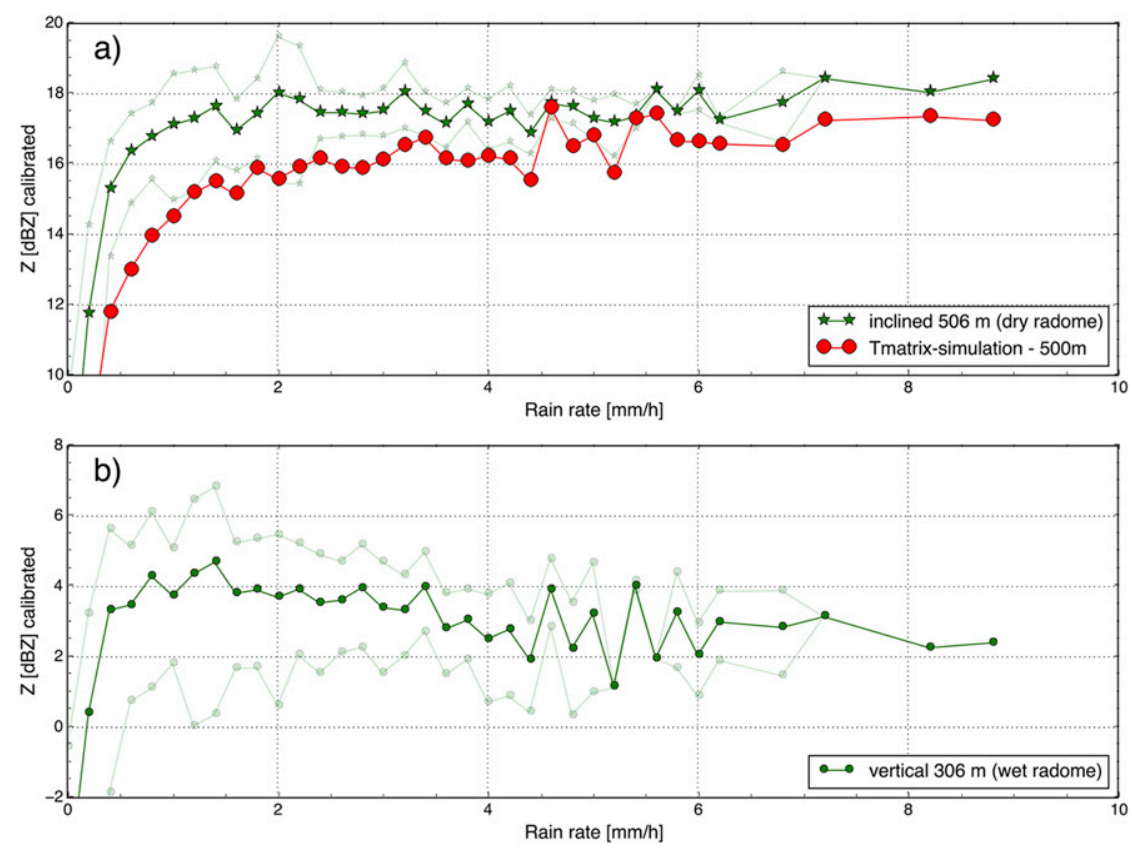

FIG. 11. Calibration verification using rain echo and rain-rate and drop size measurements. BASTA-SIRTA is pointing vertically, while BASTA-MOBILE is inclined and protected from rain. The average value of calibrated reflectivity of both radars as a function of rain rate at (a) 306 (vertical) and (b) $506 \mathrm{~m}$ (inclined $30^{\circ}$ ) range. Red line in (a) represents the simulated attenuated reflectivity at $500 \mathrm{~m}$, using the measured drop size distribution T-matrix calculation assuming an aspect ratio as a function of diameter (Beard and Chuang 1987).

protected the radome using a shelter. The same protocol is repeated here with the BASTA-MOBILE tilted at $30^{\circ}$ elevation and the radome protected from rain as shown in Fig. 1e).

Figure 11 shows the data collected for two rain events (6 and 8 October 2014). The average calibrated reflectivity at about 300 (Fig. 11a, inclined) and $500 \mathrm{~m}$ (Fig. 11b, vertical) of both radars is plotted against the rain rate. The distances used correspond to the same altitude accounting for the $30^{\circ}$ elevation. Note that we assume that the difference in attenuation is small (compared to the wet radome attenuation), and we consider that the rain field is horizontally homogeneous within a few hundred meters. Green lines represent the averaged values of reflectivity in $0.2 \mathrm{~mm} \mathrm{~h}^{-1}$ bins of rain rate, and the translucent lines indicate the standard deviation envelope. The circle and star lines correspond to the vertical radar with wet radome and inclined radar with dry radome, respectively. The red circle line illustrates the result of the attenuated reflectivity simulation at $500 \mathrm{~m}$ using drop size distribution measured by the DBS and the T-matrix calculation assuming an aspect ratio as a function of the diameter (Beard and Chuang 1987). The difference between the dry radome measurement and the T-matrix simulation for rain rate larger than $2 \mathrm{~mm} \mathrm{~h}^{-1}$ varies between 0.5 and $2 \mathrm{~dB}$. The poor comparison between reflectivity simulation and measurements below $2 \mathrm{~mm} \mathrm{~h}^{-1}$ could be explained by the fact that the rain field is less homogenous and is affected more significantly by the vertical air motion for the DBS measurements. For a proper calibration exercise, we would recommend increasing the number of rain events to enlarge the statistic. The second very important result is the effect of the wet radome, with the attenuation reaching almost $20 \mathrm{~dB}$. Note that these estimates of wet radome attenuation could be used as a proxy to correct the radar reflectivity as a function of rain rate; however, this would require a specific study with numerous rain conditions. We want to stress here that both radomes have a very similar behavior with regard to the wet radome attenuation and that the radars have been intercalibrated.

\section{Comparison with pulsed radar}

The BASTA-BOM radar was deployed at Darwin (Northern Territory, Australia) in March 2014. For 8 months the BASTA-BOM was operated alongside the DOE ARM Ka-band zenith radar (KAZR) at $34.86 \mathrm{GHz}$. We do not intend to present here an extended comparison of the radars, which will be the 
subject of further investigation. Rather, here we illustrate the performance of the BASTA on one selected cirrus case with no underlying liquid cloud layer to avoid differences due to differential attenuation at the two frequencies in liquid clouds. We also intentionally chose a drier day to minimize the impact of the gaseous attenuation correction at the two frequencies. The gaseous attenuation at 35 and $95 \mathrm{GHz}$ has been estimated using the nearest sounding and the Liebe (1985) model. Figures $12 \mathrm{a}$ and $12 \mathrm{~b}$ show the KAZR reflectivity on 17 March 2014 using the most sensitive mode (chirp mode) and the general mode. Note that although the KAZR measurements (chirp mode) start at $1800 \mathrm{~m}$ and go up to $18 \mathrm{~km}$, the comparison is limited to a maximum height of $12 \mathrm{~km}$, which corresponds to the unambiguous range of BASTA in its current configuration. Figures 12c-e show the same cloud observed by BASTA at 25, 100, and $200 \mathrm{~m}$, respectively. For that specific day, the difference in the two-way attenuation is estimated at $1.5 \mathrm{~dB}$ at $12 \mathrm{~km}$. The reflectivity of the radars has been corrected from gaseous attenuation. Note that the echoes observed by the KAZR below $2 \mathrm{~km}$ between 1000 and 1400 UTC and not by BASTA are coming from insects (Wood et al. 2009); because of their large size and their rather small concentration, the $35-\mathrm{GHz}$ radar is more sensitive to their presence. There is clearly excellent agreement between the pulsed radar and the FMCW radar observations of this ice cloud. Two periods are selected, between 1200 and 1400 UTC and between 14.5 and 15.5 UTC, where all the profiles are averaged and presented in Figs. 12f and 12g. In these profiles we clearly measure the sensitivity difference between the BASTA modes and the KAZR general and sensitive modes in the clear-air part of these profiles. In that specific case, the differences in sensitivity between the BASTA 25-, 100-, and 200-m modes and the sensitive KAZR mode (cirrus mode) are 19, 13, and $10 \mathrm{~dB}$, respectively. The difference in sensitivity between the BASTA $25-\mathrm{m}$ mode and the general KAZR mode is around $2 \mathrm{~dB}$. The sensitivity at $1 \mathrm{~km}$ of the BASTA-BOM at $25-\mathrm{m}$ resolution is about $-48 \mathrm{dBZ}$. A new mode dedicated to the tropics is currently under development. This extra capability will profile the atmosphere at $100-\mathrm{m}$ resolution with an unambiguous range at $18 \mathrm{~km}$ and an unambiguous velocity of $2.5 \mathrm{~m} \mathrm{~s}^{-1}$.

\section{Remaining issues and technical points}

We made significant progress since the beginning of the project in 2006. For instance, we abandoned the random code approach to use a chirp for modulating the signal. We also accepted losing 3-dB sensitivity by using only half of the chirp, which has proven very efficient to mitigate typical FMCW signal contamination. In addition, many minor adjustments and improvements led to the encouraging results presented in this study. However, a few artifacts remain in case of heavy rain, such as a noise increase at the far end of the profile. This can be easily removed using postprocessing algorithms. We are currently working on a solution to get rid of these artifacts associated with heavy rain, by changing the central frequency of the chirp $(I F)$. It is also important to mention that the FMCW radar is sensitive to external electromagnetic perturbation. For instance, it is crucial to ensure that the cables between the radar box and the shelter are properly isolated. The coupling effect between the antennas can also introduce artifacts, and we have limited their effects by using absorbing foam around and between the antennas and on the radar box frame. Having a bistatic radar has advantages, as we can do measurements at very short range to the radar. However, it is mandatory to accurately align the antennas in order to maximize beam overlap. To facilitate this setting, the transmitting antenna is fixed and the receiving one can be adjusted using small elevators. For example, we use the signal of a homogenous cirrus and adjust the receiving antenna until the received power is maximized.

\section{Conclusions and outlook}

In this paper we describe the BASTA cloud radar project, for which the FMCW technique is preferred to very expensive pulsed cloud radars. Since the development of the first prototype operating continuously at SIRTA since 2010, we have improved the system and built two other radars with outstanding performance. The first target of the BASTA radar was the midlatitude clouds; therefore, the maximum range was set to $12 \mathrm{~km}$. The recent deployment of the instrument in the tropics showed that given the high sensitivity of the BASTA radar, the maximum range had to be extended to $20 \mathrm{~km}$. Consequently, we are developing a new mode at 100-m resolution with a more adequate maximum range. In this mode the unambiguous velocity will be 2.5 instead of $5 \mathrm{~m} \mathrm{~s}^{-1}$. The other modes will help to correct the folding issue in the common range. The pulse-pair processing is currently done in the FPGA. We are investigating the capability to record the signal after the FFT complex calculation in order to carry spectrum analysis. This can be very useful for cloud phase discrimination (Shupe et al. 2004; Luke et al. 2010), turbulence studies (Brewster and Zrnić 1986), attenuation correction, and drop size distribution retrieval (Giangrande et al. 2010). We demonstrate that the BASTA radar is a very promising alternative to the very expensive cloud radars. As the price remains 

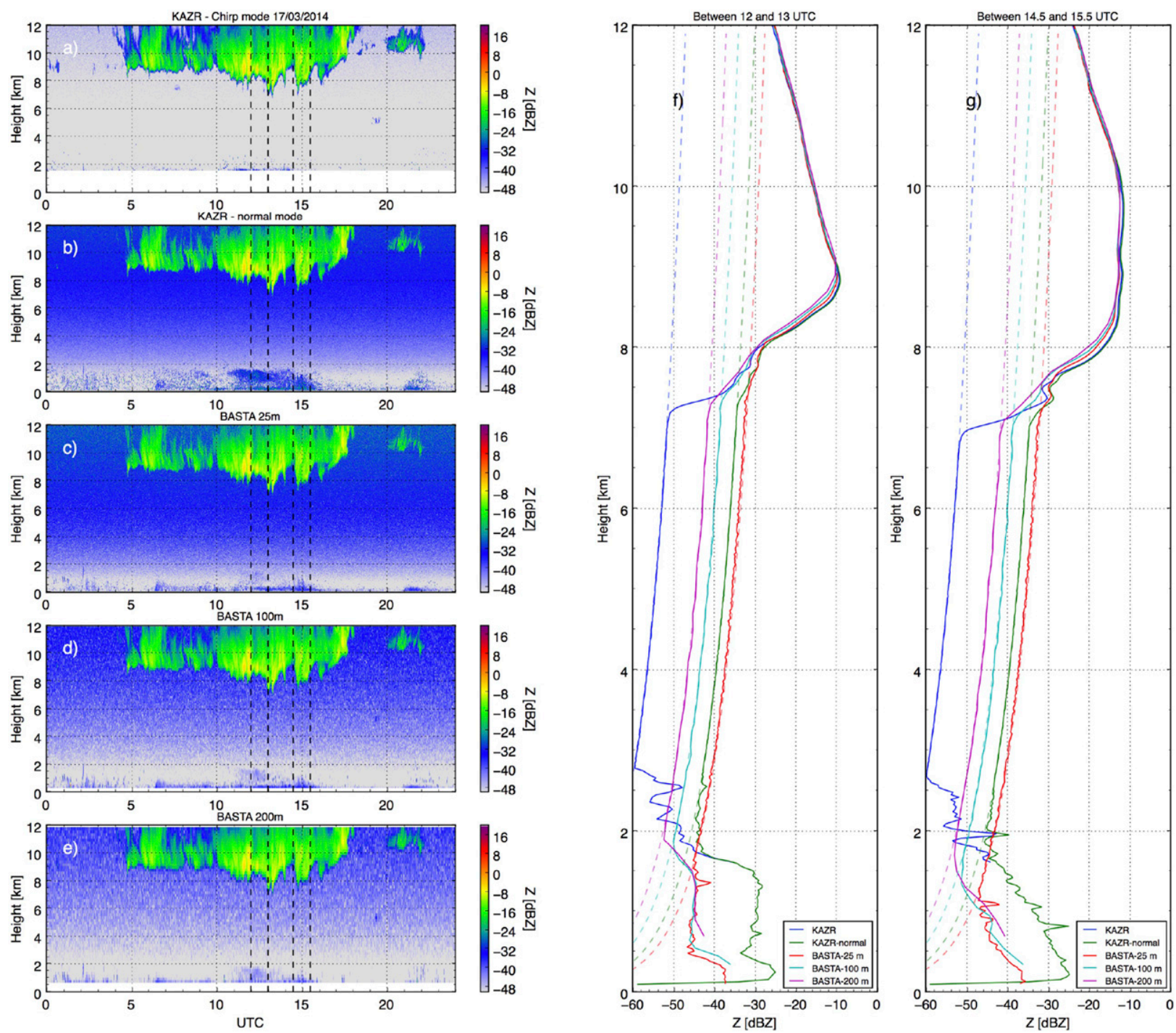

FIG. 12. Comparison of the range-corrected reflectivity at Darwin between the 35-GHz KAZR Doppler radar (a) sensitive mode and (b) normal mode, and the three BASTA modes at (c) 25-, (d) 100-, and (e) 200-m vertical resolution. Mean profiles for each radar and modes (f) between 1200 and 1300 UTC and (g) between 14.5 and 15.5 UTC. Dashed lines represent the noise level for each profile.

reasonable, it can be envisioned to develop networks of FMCW cloud radars. For instance, fog monitoring feasibility at airports using BASTA radar is currently underway. We are also experimenting with the possibility of using a BASTA radar for studying volcanic ash (Donnadieu et al. 2011; Donnadieu 2012).

Some recent experiments have been carried with the objective of analyzing whether the refractivity variability measured with W-band radar can lead to information at hectometer scales on turbulent behavior of the atmosphere. BASTA was one of the radars used during a recent campaign that took place in France at SIRTA in summer 2014. The radar was pointing horizontally toward four calibrated targets and measured the refractivity variations during two months with a sampling rate of $0.25 \mathrm{~s}$. Several instruments allowed comparison between radar refractivity measured by BASTA and in situ measurements (using Besson et al. 2012).

Acknowledgments. We are grateful to the SIRTA team, which provides day-to-day support for operating the radars and organizing the data stream. We thank Nicolas Pauwels and Christophe Legac for their help and for the fruitful discussions around the FMCW technique. We also thank Brad Atkinson for his help with the installation of BASTA-BOM in Darwin. We thank the U.S. Department of Energy as part of the Atmospheric Radiation Measurement Climate Research Facility for 
providing KAZR data. BASTA developments have been partly funded by CNES, INSU, Ecole Polytechnique, and Région Ile de France. We also acknowledge the ACTRIS and PARIFOG projects. Julien Delanoë's research is partly funded by CNES.

\section{REFERENCES}

Beard, K. V., and C. Chuang, 1987: A new model for the equilibrium shape of raindrops. J. Atmos. Sci., 44, 1509-1524 doi:10.1175/1520-0469(1987)044<1509:ANMFTE > 2.0.CO;2.

Besson, L., C. Boudjabi, O. Caumont, and J. Parent du Châtelet, 2012: Links between refractivity characteristics and weather phenomena measured by precipitation radar. Bound.-Layer Meteor., 143, 77-95, doi:10.1007/s10546-011-9656-7.

Bouniol, D., and Coauthors, 2010: Using continuous ground-based radar and lidar measurements for evaluating the representation of clouds in four operational models. J. Appl. Meteor Climatol., 49, 1971-1991, doi:10.1175/2010JAMC2333.1.

Brewster, K. A., and D. S. Zrnić, 1986: Comparison of eddy dissipation rates from spatial spectra of Doppler velocities and Doppler spectrum widths. J. Atmos. Oceanic Technol., 3, 440-452, doi:10.1175/1520-0426(1986)003<0440:COEDRF > 2.0.CO;2.

Delahaye, J.-Y., L. Barthès, P. Golé, J. Lavergnat, and J. P. Vinson, 2006: A dual-beam spectropluviometer concept. J. Hydrol. 328, 110-120, doi:10.1016/j.jhydrol.2005.11.048.

Delanoë, J., and R. J. Hogan, 2008: A variational scheme for retrieving ice cloud properties from combined radar, lidar and infrared radiometer. J. Geophys. Res., 113, D07204, doi:10.1029/ 2007JD009000.

_ A. Protat, J. Testud, D. Bouniol, A. J. Heymsfield, A. Bansemer, and P. R. A. Brown, 2007: The characterization of ice clouds properties from Doppler radar measurements. J. Appl. Meteor. Climatol., 46, 1682-1698, doi:10.1175/JAM2543.1.

— - — O. Jourdan, J. Pelon, M. Papazzoni, R. Dupuy, J.-F. Gayet, and C. Jouan, 2013: Comparison of airborne in situ, airborne radarlidar, and spaceborne radar-lidar retrievals of polar ice cloud properties sampled during the POLARCAT campaign. J. Atmos. Oceanic Technol., 30, 57-73, doi:10.1175/JTECH-D-11-00200.1.

Deng, M., and G. G. Mace, 2006: Cirrus microphysical properties and air motion statistics using cloud radar Doppler moments. Part I: Algorithm description. J. Appl. Meteor. Climatol., 45, 1690-1709, doi:10.1175/JAM2433.1.

Donnadieu, F., 2012: Volcanological applications of Doppler radars: A review and examples from a transportable pulse radar in L-band. Doppler Radar-Weather Radar, Wind Profiler, Ionospheric Radar, and Other Advanced Applications, J. Bech and J. L. Chau, Eds., InTech, 409-446, doi:10.5772/35940.

_ S. Valade, and S. Moune, 2011: Three dimensional transport speed of wind-drifted ash plumes using ground-based radar. Geophys. Res. Lett., 38, L18310, doi:10.1029/2011GL049001.

Dupont, J.-C., M. Haeffelin, A. Protat, D. Bouniol, N. Boyouk, and Y. Morille, 2012: Stratus-fog formation and dissipation: A 6-day case study. Bound.-Layer Meteor., 143, 207-225, doi:10.1007/ s10546-012-9699-4.

Giangrande, S. E., E. Luke, and P. Kollias, 2010: Automated retrievals of precipitation parameters using non-Rayleigh scattering at 95 GHz. J. Atmos. Oceanic Technol., 27, 1490-1503, doi:10.1175/2010JTECHA1343.1.

Haeffelin, M., and Coauthors, 2005: SIRTA, a ground-based atmospheric observatory for cloud and aerosol research. Ann. Geophys., 23, 253-275, doi:10.5194/angeo-23-253-2005.
— and Coauthors, 2010: ParisFog: Shedding new light on fog physical processes. Bull. Amer. Meteor. Soc., 91, 767-783, doi:10.1175/2009BAMS2671.1.

Hagen, M., and Coauthors, 2014: Airborne remote sensing of cloud properties with the German research aircraft HALO. Proc. Eighth European Conf. on Radar in Meteorology and Hydrology, Garmisch-Partenkirchen, Germany, DLR/DWD, 9b.2. [Available online at http://www.pa.op.dlr.de/erad2014/ programme/ShortAbstracts/001_short.pdf.]

Hauser, D., G. Caudal, G. Rijckenberg, D. Vidal-Madjar, G. Laurent, and P. Lancelin, 1992: Ressac: A new airborne $\mathrm{FM} / \mathrm{CW}$ radar ocean wave spectrometer. IEEE Trans. Geosci. Remote Sens., 30, 981-995, doi:10.1109/36.175333.

Hogan, R. J., D. Bouniol, D. N. Ladd, E. J. O'Connor, and A. J. Illingworth, 2003: Absolute calibration of $94 / 95-\mathrm{GHz}$ radars using rain. J. Atmos. Oceanic Technol., 20, 572-580, doi:10.1175/ 1520-0426(2003)20<572:ACOGRU>2.0.CO;2.

—, M. P. Mittermaier, and A. J. Illingworth, 2006: The retrieval of ice water content from radar reflectivity factor and temperature and its use in evaluating a mesoscale model. J. Appl. Meteor. Climatol., 45, 301-317, doi:10.1175/JAM2340.1.

Horie, H., H. Okamoto, S. Iwasaki, H. Kumagai, and H. Kuroiwa, 2000: Cloud observation with CRL airborne cloud profiling radar (SPIDER). IGARSS 2000: IEEE 2000 International Geoscience and Remote Sensing Symposium; Taking the Pulse of the Planet, T. I. Stein, Ed., Vol. 1, IEEE, 190-191, doi:10.1109/ IGARSS.2000.860464.

Huggard, P. G., and Coauthors, 2008: $94 \mathrm{GHz}$ FMCW cloud radar. Millimetre Wave and Terahertz Sensors and Technology, K. A. Krapels and N. A. Salmon, Eds., International Society for Optical Engineering (SPIE Proceedings, Vol. 7117), 711704, doi:10.1117/12.800347.

Illingworth, A. J., and Coauthors, 2007: Cloudnet: Continuous evaluation of cloud profiles in seven operational models using ground-based observations. Bull. Amer. Meteor. Soc., 88, 883898, doi:10.1175/BAMS-88-6-883.

— , and Coauthors, 2015: The EarthCARE satellite: The next step forward in global measurements of clouds, aerosols, precipitation, and radiation. Bull. Amer. Meteor. Soc., 96, 1311-1332, doi:10.1175/BAMS-D-12-00227.1.

Kollias, P., E. E. Clothiaux, M. A. Miller, B. A. Albrecht, G. L. Stephens, and T. P. Ackerman, 2007a: Millimeter-wavelength radars: New frontier in atmospheric cloud and precipitation research. Bull. Amer. Meteor. Soc., 88, 1608-1624, doi:10.1175/ BAMS-88-10-1608.

, M. A. Miller, E. P. Luke, K. L. Johnson, E. E. Clothiaux, K. P. Moran, K. B. Widener, and B. A. Albrecht, 2007b: The Atmospheric Radiation Measurement Program cloud profiling radars: Second-generation sampling strategies, processing, and cloud data products. J. Atmos. Oceanic Technol., 24,11991214, doi:10.1175/JTECH2033.1.

Lhermitte, R., 1990: Attenuation and scattering of millimeter wavelength radiation by clouds and precipitation. J. Atmos. Oceanic Technol., 7, 464-479, doi:10.1175/1520-0426(1990)007<0464: AASOMW $>2.0 . \mathrm{CO} ; 2$.

Li, L., and Coauthors, 2001: Retrieval of atmospheric attenuation using combined ground-based and airborne 95-GHz cloud radar measurements. J. Atmos. Oceanic Technol., 18, 1345-1353, doi:10.1175/1520-0426(2001)018<1345: ROAAUC $>2.0 . \mathrm{CO} ; 2$.

Liebe, H. J., 1985: An updated model for millimeter wave propagation in moist air. Radio Sci., 20, 1069-1089, doi:10.1029/ RS020i005p01069. 
Ligthart, L. P., L. R. Nieuwkerk, and J. S. Vansinttruyen, 1986: Basic characteristics of FM-CW radar systems. Multifunction radar for airborne applications, AGARD Conference Proceedings 381, AGARD-CP-381, NATO, 11 pp.

Löhnert, U., S. Crewell, C. Simmer, and A. Macke, 2001: Profiling cloud liquid water by combining active and passive microwave measurements with cloud model statistics. J. Atmos. Oceanic Technol., 18, 1354-1366, doi:10.1175/1520-0426(2001)018<1354: PCLWBC $>2.0 . C O ; 2$.

Luke, E., P. Kollias, and M. D. Shupe, 2010: Detection of supercooled liquid in mixed-phase clouds using radar Doppler spectra. J. Geophys. Res., 115, D19201, doi:10.1029/2009JD012884.

Maier, F., J. Bendix, and B. Thies, 2012: Simulating $Z$-LWC relations in natural fogs with radiative transfer calculations for future application to a cloud radar profiler. Pure Appl. Geophys., 169, 793-807, doi:10.1007/s00024-011-0332-0.

Matrosov, S. Y., and A. J. Heymsfield, 2000: Use of Doppler radar to assess ice cloud particle fall velocity-size relations for remote sensing and climate studies. J. Geophys. Res., 105, 22 427-22 436, doi:10.1029/2000JD900353.

Moran, K. P., B. E. Martner, M. J. Post, R. A. Kropfli, D. C. Welsh, and K. B. Widener, 1998: An unattended cloud-profiling radar for use in climate research. Bull. Amer. Meteor. Soc., 79, 443-455, doi:10.1175/1520-0477(1998)079<0443:AUCPRF>2.0.CO;2.

O'Connor, E. J., R. J. Hogan, and A. J. Illingworth, 2005: Retrieving stratocumulus drizzle parameters using Doppler radar and lidar. J. Appl. Meteor., 44, 14-27, doi:10.1175/JAM-2181.1.

Protat, A., J. Delanoë, D. Bouniol, A. J. Heymsfield, A. Bansemer, and P. Brown, 2007: Evaluation of ice water content retrievals from cloud radar reflectivity and temperature using a large airborne in situ microphysical database. J. Appl. Meteor. Climatol., 46, 557-572, doi:10.1175/JAM2488.1.

Sami, G., 2009: Radio wave propagation characteristics in FMCW radar. J. Electromagn. Anal. Appl., 1, 275-278, doi:10.4236/ jemaa.2009.14042.
Sekelsky, S. M., 2002: Near-field reflectivity and antenna boresight gain corrections for millimeter-wave atmospheric radars. J. Atmos. Oceanic Technol., 19, 468-477, doi:10.1175/ 1520-0426(2002)019<0468:NFRAAB > 2.0.CO;2.

Shupe, M., P. Kollias, S. Y. Matrosov, and T. L. Schneider, 2004: Deriving mixed-phase cloud proper ties from Doppler radar spectra. J. Atmos. Oceanic Technol., 21, 660-670, doi:10.1175/1520-0426(2004)021<0660: $\mathrm{DMCPFD}>2.0 . \mathrm{CO} ; 2$.

Stephens, G. L., and Coauthors, 2002: The Cloudsat Mission and the A-Train: A new dimension of space-based observations of clouds and precipitation. Bull. Amer. Meteor. Soc., 83, 17711790, doi:10.1175/BAMS-83-12-1771.

Thies, B., K. Müller, F. Maier, and J. Bendix, 2010: Fog monitoring using a new $94 \mathrm{GHz}$ FMCW cloud radar. Proc., Fifth Int. Conf. on Fog, Fog Collection and Dew, Münster, Germany, DFG, FOGDEW2010-103. [Available online at http://meetingorganizer.copernicus.org/FOGDEW2010/ FOGDEW2010-103.pdf.]

Williams, C. R., 2011: Inexpensive FM-CW radar for boundarylayer precipitation studies. IEEE Geosci. Remote Sens. Lett., 8, 1031-1035, doi:10.1109/LGRS.2011.2150733.

Wolde, M., and A. Pazmany, 2005: NRC dual-frequency airborne radar for atmospheric research. 32nd Conf. on Radar Meteorology, Albuquerque, NM, Amer. Meteor. Soc., P1R.9. [Available online at https://ams.confex.com/ams/32Rad11Meso/techprogram/ paper_96918.htm.]

Wood, C. R., E. J. O'Connor, R. A. Hurley, D. R. Reynolds, and A. J. Illingworth, 2009: Cloud-radar observations of insects in the UK convective boundary layer. Meteor. Appl., 16, 491500, doi:10.1002/met.146.

Yamaguchi, J., and Coauthors, 2006: Sensitivity of FMCW 95Ghz cloud radar for high clouds. 2006 Asia-Pacific Microwave Conference Proceedings, Vol. 3, IEEE, 1841-1846, doi:10.1109/ APMC.2006.4429767. 